\title{
GEOLOCATION: LOCATING TRUST IN DIGITAL PLATFORMS AND ECONOMIES
}

\author{
Peta Mitchell \\ Queensland University of Technology \\ Agnieszka Leszczynski \\ Western University \\ Matthew Zook \\ University of Kentucky, Geography \\ Joe Blankenship \\ University of Kentucky, Geography \\ Caitlin McGrane \\ RMIT University \\ Larissa Hjorth \\ RMIT University \\ Julian Thomas \\ RMIT University \\ Rowan Wilken \\ RMIT University
}

\section{Panel overview}

Many of our quotidian digital practices are thoroughly mediated by digital location, including the ways in which we make our ways across cities; how we consume products, services, and content; and how we participate on social media.

Suggested Citation (APA): Mitchell, P., Leszczynski, A., Zook, M., Blankenship, J., McGrane, C., Hjorth, L., Wilken, R., \& Thomas, J. (2019, October 2-5). Geolocation: Locating trust in digital platforms and economies. Panel presented at AolR 2019: The $20^{\text {th }}$ Annual Conference of the Association of Internet Researchers. Brisbane, Australia: AolR. Retrieved from http://spir.aoir.org. 
Simultaneously, it has been estimated that up to 80 per cent of big data productions are spatial-i.e., they include a locational component (see Leszczynski \& Crampton 2016). Both of these phenomena are underwritten by the ways in which digital location-or simply geolocation-has become an established fixture of digital devices, platforms, and economies: GPS chips are native components of smartphones; digital platforms routinely extend geotagging capabilities to users; mobile apps organize content and user experiences around map-based interfaces; and 'disruptive' market actors such as Uber and Airbnb rely on geolocation affordances as a core component of their services.

To date, much of the public and academic conversation about geolocation has converged around privacy concerns arising from the ways in which individuals' highly sensitive personal location data is continuously harvested, captured, generated, disclosed, hacked, and repurposed within a networked ecosystem of connected devices, sensor-seeded environments, third-party applications, and a burgeoning data brokerage industry organized around the purchase and resale of personal location data trails, often without users' knowledge or consent (e.g., Kitchin, 2015; Leszczynski, 2017; Light et al., 2018; Mims, 2018; Mitchell \& Highfield, 2017; Valentineo-DeVries et al. 2018).

Yet the narrow focus on these geoprivacy issues has obscured the key role that geolocation, as a central component of data and digital media, has in securing and eroding trust in digital platforms and economies, both materially and discursively. This panel starts from the premise that geolocation is both a 'technology of trust' (Withers 2018, p. 490)—or a sociotechnical agent by which digital systems present and build themselves as trustworthy_and a social relation of trustworthiness. This panel brings together papers that engage with geolocation and (mis)trust in both of these senses of sociotechnical agents and social relations of trust in digital systems, with an emphasis on platforms and economies.

[Paper 1] fleshes out the panel's overarching premise by empirically identifying, across a range of platforms, the ways in which geolocation affordances, technologies, and location-based services are being leveraged to actively build trust in digital platforms. In doing this, this paper makes the case for geolocation as a central, though often overlooked, technology of trust leveraged by platforms and functioning as a vital assemblant of 'platform affects' around trust, security, and risk.

[Paper 2] turns its focus to the locations and spatialities of blockchain-enabled cryptocurrencies. Through mapping and analysing the emerging geographies of cryptocurrency, this paper reveals how these crypto-geographies are thoroughly entangled with formations and practices of trust-and its uneven development-in the digital (crypto)economy.

In its close analysis of Uber's recently launched 'Safety Toolkit', which enables users to share their real-time location with trusted contacts, [Paper 3] pulls focus both to the particular social relations of trust engendered in and through location-based services designed for trust and the gendered affective labour that navigating this 'careful surveillance' entails on the part of users. 
Once again foregrounding geolocation as a 'technology of trust', our final paper in this panel examines how maps and map data have long underpinned the development of human trust in and control of vehicles. Particularly in the case of autonomous vehicles [Paper 4] maintains, geolocation is not simply a 'layer on top of autonomous vehicle systems', but is 'integral to their operation [and] crucial to the future trustworthiness-or otherwise-of these systems'.

\section{References}

Kitchin, R. (2015). Continuous geosurveillance in the "smart city". DIS magazine. http://dismagazine.com/dystopia/73066/rob-kitchin-spatial-big-data-andgeosurveillance/.

Lee, M. K. (2018). Understanding perception of algorithmic decisions: Fairness, trust, and emotion in response to algorithmic management. Big Data \& Society. doi: $10.1177 / 2053951718756684$.

Leszczynski, A. (2017). Geoprivacy. In Kitchin R., Wilson M. W. \& Lauriault, T. P. (eds.) Understanding spatial media (pp. 235-244). SAGE.

Leszczynski, A. \& Crampton, J. (2016). Spatial big data and everyday life. Big Data \& Society 3(2). doi: 10.1177/2053951716661366.

Light, B., Mitchell, P., \& Wikström, P. (2018). Big data, method and the ethics of location: A case study of a hookup app for men who have sex with men. Social Media + Society, doi: 10.1177/2056305118768299

Mims, C. (2018, March 4). Your location data is being sold-Often without your knowledge. Wall Street Journal. https://www.wsi.com/articles/your-location-data-isbeing-soldoften-without-your-knowledge-1520168400

Mitchell, P. \& Highfield, T. (2017). Mediated geographies of everyday life: Navigating the ambient, augmented, and algorithmic geographies of geomedia. Ctrl-Z: New Media Philosophy 7. http://www.ctrl- z.net.au/journal/?slug=mitchell-highfield-mediatedgeographies-of-everyday-life

Valentineo-DeVries, J., Singer, N., Keller, M. H., \& Krolik, A. (2018, December 10). Your apps know where you were last night, and they're not keeping it secret. New York

Times. https://www.nytimes.com/interactive/2018/12/10/business/location-data-privacyapps.html?action=click\&module=Top $\% 20$ Stories\&pgtype=Homepage

Withers, C. W. J. (2018). Trust - in geography. Progress in Human Geography 42(4): 489-508. doi: 10.1177/0309132516688078 


\title{
1. GEOLOCATION, TRUST, AND PLATFORM AFFECTS
}

\author{
Agnieszka Leszczynski \\ Western University \\ Peta Mitchell \\ Queensland University of Technology
}

This paper engages the intensifying incorporation of digital location data, interfaces, and affordances as pervasive features of digital platforms by positioning geolocation as a vital assemblant of 'platform affects'. We theorize platform affects as collective and individual orientations of attunement, predisposition, and/or incentivization towards participating on, remaining within, and/or returning to platforms. Trust and security are two key instrumentalities that work to so invest users in digital platforms by making these systems "'[feel] right"” to users (Pink et al., 2018, p. 3). As we demonstrate in this paper, digital location affordances, utilities, and services have emerged as indispensable technics and discursive agents by which platform affects of security and trust are assembled for and by digital platforms, extending to users "a sense of control in [spaces] of uncertainty" that resolves for them ambiguities about participating on, using, or repeat engaging with digital platforms (Pink et al., 2018, p. 3).

Trust is also, inherently and inescapably, connected with risk. Trust is not an absence of risk but rather presupposes the existence of and the need to negotiate risk. As Niklas Luhmann (1979) puts it in his major theoretical work Trust and Power, 'trust is not concerned with knowing the essential truth about a matter but [...] with the fact that the taking of the risk involved has proved itself in social life and thus becomes a motivating force, which yields further attestation' (p. 76). The increasingly well-publicised risks to user privacy that attend geolocation (e.g., Mims, 2018; Valentineo-DeVries et al., 2018) can therefore be seen, almost paradoxically, as effectively underpinning rather than simply undermining these platform affects of security and trust.

Drawing on empirical examples, we foreground geolocation as one of the central, though often overlooked, sociotechnical agencies leveraged and operationalized by platforms to materially realize and discursively present themselves as trustworthy. In positioning geolocation as something used to engender trust in data and platforms, we simultaneously mobilize theories and approaches that foreground the affective, social, and interactional aspects of trust in order to draw attention to trust's geolocational dimensions. By the latter, we refer to what Withers (2018) has recently referred to as

'thick relationships' ... 'grounded in a complex of overlapping iterated interactions' (Hardin, 2002: 21), either within a small and perhaps geographically proximal community or, over distance, in persons with whom we have reason to trust. This is to hint at two expressions of trust's geographical dimensions - its making in social groups and its inscription over space. It also alerts us to the key issue of trustworthiness. (p. 494)

Withers begins the work of bringing geolocation and trust into the same frame, raising key questions about the relationships between the two. And yet, while Withers (2018) 
calls for further evaluation of the "ways in which trust and trustworthiness are secured the 'technologies of trust"' (p. 490), he does not address the very contemporary ways in which trust is secured in and through geolocative technologies and platforms. Elsewhere, within digital media studies, emerging research has focussed on the complex arrangements of trust built and negotiated between users, digital platforms, and algorithms (e.g., Lee, 2018; Ostherr et al., 2017; Pink et al., 2018). Importantly, this body of work advances an understanding of trust as first and foremost affective - it "entails feeling and knowing enough to be able to take the next step" forward in the moment (Pink et al., 2018, p. 3). This pursuit of something that 'feels right' in the "space of uncertainty" characteristic of networked platform ecologies is "part of how we live with data" and digital systems more generally (Pink et al., 2018, p. 3). Yet here, too, the particular role of geolocation in assembling these arrangements remains to be addressed.

We address this significant gap by empirically identifying the ways in which geolocation affordances, technologies, and location-based services are being leveraged to actively build trust in digital platforms and in data. These material and discursive practices include leveraging geolocation for purposes of digital securitization (securing digital transactions), authentication (verification of identity), care (ensuring safety), and trustworthy sociality (trust in digitally-brokered social interactions). We provide realworld examples of each of these operationalizations of geolocation in service of securitization, authentication, care, and trustworthy sociality to substantiate our heuristic. In so doing, we cast geolocation as an instrumentality that organizes affects of security and trust for digital systems and digital economies. Through engaging the intersections of geolocation and digital platforms via an analytic of affect, this paper provides specificity and explanatory power to not only the "dynamics driving the integration of geographic information into the digital economy” (Alvarez León 2016, p. 1 ), but also to the affective and emotional dynamics of how we, both individually and collectively, are mobilized and incentivized to continuously engage-and reengagewith digital systems as part of our everyday life practices.

\section{References}

Alvarez León, L.F. (2016). Property regimes and the commodification of geographic information: An examination of Google Street View. Big Data \& Society 3(2): 1-13. doi: $10.1177 / 2053951716637885$.

Lee, M. K. (2018). Understanding perception of algorithmic decisions: Fairness, trust, and emotion in response to algorithmic management. Big Data \& Society. doi: $10.1177 / 2053951718756684$.

Luhmann, N. (1979). Trust and Power. Trans. of Vertrauen (1973) and Macht (1975). Trans. H Davies, J. Raffan, \& K. Rooney. John Wiley and Sons.

Mims, C. (2018, March 4). Your location data is being sold-Often without your knowledge. Wall Street Journal. https://www.wsj.com/articles/your-location-data-isbeing-soldoften-without-your-knowledge-1520168400 
Ostherr, K., Borodina, S., Bracken, R. C., Lotterman, C., Storer, E., \& Williams, B. (2017). Trust and privacy in the context of user-generated health data. Big Data \& Society. doi: 10.1177/2053951717704673.

Pink, S., Lanzeni, D., \& Horst, H. (2018). Data anxieties: Finding trust in everyday digital mess. Big Data \& Society. doi: 10.1177/2053951718756685.

Valentineo-DeVries, J., Singer, N., Keller, M. H., \& Krolik, A. (2018, December 10). Your apps know where you were last night, and they're not keeping it secret. New York

Times. https://www.nytimes.com/interactive/2018/12/10/business/location-data-privacyapps.html?action=click\&module=Top $\% 20$ Stories \&pgtype=Homepage

Withers, C. W. J. (2018). Trust - in geography. Progress in Human Geography 42(4): 489-508. doi: 10.1177/0309132516688078 


\title{
2. CRYPTO-GEOGRAPHIES: LOCATING THE TECHNICAL AND SOCIAL DIMENSIONS OF BLOCKCHAIN
}

\author{
Matthew Zook \\ University of Kentucky, Geography \\ Joe Blankenship \\ University of Kentucky, Geography
}

In less than a decade blockchain-based cryptocurrencies such as Bitcoin have gained worldwide attention due to their astronomical and volatile values as well as their aspirations to replace state-based fiat currencies with decentralized systems of algorithmic governance and trust (Nakamoto, 2008). Much less well understood is the spatiality of these new financial systems and how they contribute to shifting patterns of wealth accumulation, trust and market exchange. To address this gap, this paper locates core cryptocurrency functions within code/space and ongoing processes of financialization. In addition to addressing fundamental questions about the locations of cryptocurrency operations, this paper also asks, What material and organizational factors contribute to these geographies? and How are locations integrated within upstream and downstream operations such as software development and ICOs? By studying the spatial and digital organization of these new practices this paper provides much needed insight on how cryptocurrencies contribute to the location and practice of trust within economies, currencies and finance.

\section{Conceptualizing Cryptocurrencies via Financialization and Code/Space}

Aalbers (2017) defines financialization as the "...increasing dominance of financial actors, markets, practices, measurements and narratives, at various scales, resulting in a structural transformation of economies, firms (including financial institutions), states and households." As a conceptual framing, financialization focuses on how financial logics shape social, cultural and spatial practices that ultimately manifest in firms' and individuals' economic behavior (Hall, 2012; Lai, 2017). This paper focuses on the spatial propagation of the financial logics of cryptocurrencies and which places and actors are entangled.

To empirically measure these geographies of cryptocurrencies, this paper draws upon Kitchin and Dodge's (2014) theory of code/space in which software and materiality come together in the production of space, blending human and software decisions. This intertwining of software and materiality is readily evident in blockchain-based cryptocurrencies. These code/spaces enroll technical structures (blockchain miners) that tied to material inputs (electricity and computer hardware) as well as social inputs (attention, labor, trust, ICOs, etc.). For example, computer miners running proof-of-work algorithms rely on computational power to solve the hash encryptions (de Vries, 2018) and as cryptocurrencies gained monetary value, a hardware-driven, energy intensive arms race emerged. The key role of electricity results in geographies based on energy costs, manifesting in massive Chinese computer networks organized around state- 
subsidized power (Fairley, 2017) and malware designed to hijack computer cycles from personal computers (Lau, 2017).

An example of social input shaping the geographies of cryptocurrencies is the labor (by developers, exchange owners and entrepreneurs) which creates and uses blockchain systems. While blockchain developers have largely clustered in the USA and Europe (Friedlmaier et al., 2017), the code/spaces of engagement rely heavily on digital communication—chat, email, message boards, video calls—to create networks spanning the globe (Castells, 1996) contrasting to previous patterns of tech-based startups (Storper, 1997). Closely tied to these configurations are evolving regimes of regulation that help shape the locational decisions of cryptocurrency activities. States and central banks are still coming to terms on how to treat cryptocurrencies, e.g., are they assets, securities or something else, and this drives firms structures and geographies.

\section{Analyzing Cryptocurrency Geographies}

The spatial organization of cryptocurrencies is relatively unknown as there are no comprehensive data repositories on the locations of its activities even as it spreads globally. To address this gap, this paper analyzes and visualizes three cryptocurrency geographies essential building trust and functionality in the system: computer miners, attention to cryptocurrencies and blockchain developers.

- Mapping cryptocurrency miners: Computer nodes or miners on which blockchain and encryption protocols run are central to cryptocurrencies. This paper's builds upon the Bitnode (2018) technique supplemented by web crawling of available mining pool APIs to create a list of all miners for the Bitcoin network. Standard IP geolocation services will determine the location of miners at a range of accuracies from country to city level. Because power cost is an important driver of miner locations (Fairley, 2017) this paper tests the extent to which electricity pricing is correlated to miners' locations.

- Locating attention to cryptocurrencies: Attracting and selling attention is central to many business models (Wu 2017) but for cryptocurrencies garnering attention and engagement is a key input to building trust and value. Attention, is a limited resource and understanding where attention manifests (Karpick 2010) offers key insight on the spatiality of cryptocurrencies. Using a global database of geotagged social media since this paper uses tweets and profiles based on a curated list of cryptocurrency keywords to identify attention to cryptocurrencies across scales.

- Finding blockchain developers: Existing literature (Garcia et al., 2014) suggests that the geographies of the labor behind the development of blockchain are remarkably diffuse. Project work is organized and conducted remotely via global networks contrasting to previous patterns of localized agglomerations based on labor, cultural practices, knowledge or capital (Storper, 1997). To trace the geographies of blockchain developers this project uses two publicly available sources: Linkedln profiles and Github project profiles to create a database of blockchain developers. 
Using these bespoke datasets this paper presents a series of mappings (cartographic and relational) to highlight the often-unseen geographies of software and information technology practices (see Graham et al, 2015 for a similar approach). With these visualizations the paper casts light on this new shadowy yet growing system of global finance is organizing itself and unevenly building trust in new currencies and connecting locations around the world.

\section{Bibliography}

\section{References}

Aalbers, M. B. (2016). Corporate financialization. International Encyclopedia of Geography, 1-11.

Castells, M. (1996). The Rise of the Network Society. Wiley Blackwell.

de Vries, A. (2018). Bitcoin's growing energy problem. Joule 2(5): 801-805.

Fairley, P. (2017). Feeding the blockchain beast. IEEE Spectrum 54(10): 36-59.

Friedlmaier, M., Tumasjan, A., \& Welpe, I. M. (2017). Disrupting industries with blockchain: The industry, venture capital funding, and regional distribution of blockchain ventures. Available from SSRN: https://ssrn.com/abstract=2854756,

Garcia, D., Tessone, C.J., Mavrodiev, P., \& Perony, N. (2014). The digital traces of bubbles: Feedback cycles between socio-economic signals in the Bitcoin economy. Journal of the Royal Society: Interface 11: 1-8.

Graham, M., Sabbata, S., \& Zook, M. (2015). Towards a study of information geographies: Immutable augmentations and a mapping of the geographies of information. Geo: Geography and Environment. DOI:10.1002/geo2.8/epdf

Hall, S. (2012). Geographies of money and finance II - Financialization and financial subjects. Progress in Human Geography 36(3): 403-411.

Karpick, L. (2010). Valuing the unique: The economics of singularities. Princeton: Princeton University Press.

Kitchin, R., \& Dodge, M. (2014). Code/space: Software and everyday life. Cambridge, MA: The MIT Press. 
Lai, K. (2017). Financialisation of everyday life, In: Clark, G.L., Feldmann, M., Gertler, M.S. \& Wojcik, D. (eds) The New Oxford Handbook of Economic Geography, Oxford: Oxford University Press

Lau, H. (2017). Browser-based cryptocurrency mining makes unexpected return from the dead. Symantec Blogs. https://www.symantec.com/blogs/threatintelligence/browser-mining-cryptocurrency,

Nakamoto, S. (2008). Bitcoin: A peer-to-peer electronic cash system. Retrieved from: https://bitcoin.org/

Storper, M. (1997). The regional world: Territorial development in a global economy. Guilford press.

Wu, T. (2017). The attention merchants: From the daily newspaper to social media, how our time and attention is harvested and sold. London: Atlantic. 


\title{
3. LOCATING WOMEN'S SAFETY IN UBER'S “SAFETY TOOLKIT”
}

\author{
Caitlin McGrane \\ RMIT University
}

Larissa Hjorth

RMIT University

Smartphones are very much part of everyday (Deloitte, 2016). They operate in a paradoxical manner-at sometimes empowering, other times exploiting, sometimes personal, other times corporatised-highlighting some of the key practices of datafication (van Dijck, 2014). They are vehicles for what Melissa Gregg calls context bleed (2011)—creating new forms of "mobile intimacy" and informal labour practices. They are also both companion and witnesses to changing relationships between intimacy, informal labour and data.

These paradoxes are amplified in the case of gendered use whereby they can be both affective tools for protection (Cumiskey \& Brewster, 2012) and surveillance (Frith, 2015). As data and everyday life become entangled, we start to see different modes of affective labour coming to the forefront. Affective labour is typically characterised as emotional work women are forced to do to make people feel at ease (Hochschild, 1983), including smiling or ignoring their own discomfort for the sake of others. These practices become normalized and domesticated in, and through, smartphones (Fortunati, 2011).

As part of the rise of datafication in everyday life through the smartphone has been the default role of GPS. Locative media, deployed through smartphones, are shaping new understandings of space (de Souza e Silva \& Frith, 2012), surveillance (Humphreys,

2013,2011 ) and rethinking privacy (Gazzard, 2011). Although scholars have examined corporate and governmental surveillance in an age of Big Data (e.g. Farman, 2011; Andrejevic, 2006, 2013; Lupton, 2016), new forms of social surveillance (Marwick, 2012) amongst families or couples creates an additional-and, to date, underresearched-overlay of everyday practices (Hjorth et al., 2017; Leaver, 2017).

For example, we know little about the ways locative media practices relate to privacy, intimacy and surveillance, and how these experiences play out in terms of gendered labour. How do locative media overlays in everyday life shape, and are shaped by, women? And how is affective labour recalibrated through these experiences and practices? These questions are particularly pertinent when thinking about locative media apps such as Uber (Hjorth et al., 2018).

This paper focuses on gendered affective labour and locative media in the context of Uber end-users. Previous research has found that Uber drivers feel they must constantly be "friendly" while working, performing particular modes of affect (Anderson, 2016; Rosenblat \& Stark, 2016), but little is known about the affective labour of Uber passengers. In particular, we investigate the norms and procedures of Uber's "Safety Toolkit". 
Uber's "Safety Toolkit" includes a number of measures aimed to increase the feelings of safety for end-users. These included an "emergency button" to contact authorities, and "Trusted Contacts" to share real-time location. While these can be interpreted as "careful surveillance" practices (Hjorth, Richardson, \& Balmford, 2016), they also suggest that the trade-off for improved safety is increased surveillance. "Careful surveillance" refers to the ways we carefully and deliberately watch those who are subject to our care (Hjorth, Richardson, \& Balmford, 2016). However, as smartphones and location data can be used for surveillance (Frith, 2015), these practices are intended to create affective labour for Uber users because the platform cannot be trusted to adequately protect them.

Uber frames the "Safety Toolkit" as careful surveillance on a user-to-user basis, however this assumes passengers should trust Uber to protect and manage their data. In its privacy policy, Uber states it prevents fraud by sharing user data with third parties, but does not provide further details (Uber, 2019). Without knowing exactly how and why Uber is collecting their data, users cannot assume their privacy is being protected. Instead of users unquestioningly placing trust in Uber, there needs to be closer scrutiny of Uber's data practices.

In this paper we discuss Uber's "Safety Toolkit" to unpack how it profits from user data and trust in their safety features. We then explore ethnographically how Uber's affective labour is perceived by women end-users. Do women feel safe? What constitutes "feeling" safe? What are the invisible and tacit multisensorial dimensions that constitute those feelings and affects? Deploying interviews, scenarios of use and application, we explore some of the paradoxical ways women are experiencing Uber and its affective labour.

\section{References}

Anderson, D. N. (2016). Wheels in the head: Ridesharing as monitored performance. Surveillance \& Society 14(2): 1477-1487.

Andrejevic, M. (2013). Infoglut: How too much information is changing the way we think and know. New York: Routledge.

Cox, J. (2019). I gave a bounty hunter $\$ 300$. Then he located our phone. Motherboard. Retrieved from https://motherboard.vice.com/en us/article/nepxbz/i-gave-a-bountyhunter-300-dollars-located-phone-microbilt-zumigo-tmobile

Cumiskey, K. M., \& Brewster, K. (2012). Mobile phones or pepper spray. Feminist Media Studies 12(4): 590-599. doi:10.1080/14680777.2012.741893

Deloitte. (2016). Mobile consumer survey 2016: The Australian cut. Retrieved from https://www2.deloitte.com/au/en/pages/technology-media-andtelecommunications/articles/mobile-consumer-survey-2016.html

de Souza e Silva, A., \& Frith, J. (2012). Mobile interfaces in public spaces: Locational privacy, control, and urban sociability. New York: Routledge. 
Fortunati, L. (2009). Gender and the mobile phone. In L. Hjorth \& G. Goggin (Eds.), Mobile technologies: From telecommunications to media (pp. 23-34). New York:

Routledge.

Fortunati, L. (2011). ICTs and immaterial labor from a feminist perspective. Journal of Communication Inquiry 35(4): 426-432. doi:10.1177/0196859911417713

Frith, J. (2015). Smartphones as locative media. Cambridge, UK: Polity Press. Goldenfein, J. (2017). Australia's privacy laws gutted in court ruling on what is 'personal information'. The Conversation. Retrieved from https://theconversation.com/australiasprivacy-laws-gutted-in-court-ruling-on-what-is-personal-information-71486

Gregg, M. (2011). Work's intimacy. Cambridge, UK: Polity.

Hjorth, L., Horst, H., \& Pink, S. (2018). Privacy at the margins. International Journal of Communication 12. Retrieved from https://ijoc.org/index.php/ijoc/article/view/7050

Hjorth, L., Richardson, I., \& Balmford, W. (2016). Careful surveillance and pet wearables: at home with animals. The Conversation. Retrieved from https://theconversation.com/careful-surveillance-and-pet-wearables-at-home-withanimals-63883

Hochschild, A. (1983). The managed heart. Berkeley: University of California Press

Humphreys, L. (2011). Who's watching whom? A study of interactive technology and surveillance. Journal of Communication 61(4): 575-595. doi: 10.1111/j.14602466.2011.01570.x

Humphreys, L. (2013). Mobile social networks and surveillance: Users' perspectives. In A. Jansson \& M. Christensen (Eds.), Media, surveillance, and identity: A social perspective (pp. 109-126). New York: Peter Lang.

Jacks, T. (2019). Female ride-share drivers campaign for safer working conditions. Sydney Morning Herald. Retrieved from https://www.smh.com.au/business/workplace/female-ride-share-drivers-campaign-forsafer-working-conditions-20180718-p4zs96.html

Khosrowshahi, D. (2018). Getting serious about safety. Retrieved from https://www.uber.com/newsroom/getting-serious-safety/

Leaver, T. (2017). Intimate surveillance: Normalizing parental monitoring and mediation of infants online. Social Media + Society 3(2): 1-10.

Levine, Y. (2018). Google's Earth: How the tech giant is helping the state spy on us. Retrieved from https://www.theguardian.com/news/2018/dec/20/googles-earth-how-thetech-giant-is-helping-the-state-spy-on-us 
Location Forum (2013). Location data privacy: Guidelines, assessment \& recommendations.

Lupton, D. (2016a). The diverse domains of quantified selves: Self-tracking modes and dataveillance. Economy and Society 45(1), 101-122.

Reply All (2019). Robocall: Bang bang. Retrieved from https://www.gimletmedia.com/reply-all/135-the-robocall-conundrum

Rosenblat, A., \& Stark, L. (2016). Algorithmic labor and information asymmetries: A case study of Uber's drivers. International Journal of Communication 10: 3758-3784. doi:10.1111/tsq.12101

Uber. (2019). Privacy Policy. Retrieved 1 February, 2019 from

https://privacy.uber.com/policy/

Valentineo-DeVries, J., Singer, N., Keller, M. H., \& Krolik, A. (2018, December 10). Your apps know where you were last night, and they're not keeping it secret. New York Times. https://www.nytimes.com/interactive/2018/12/10/business/location-data-privacyapps.html?action=click\&module=Top \%20Stories\&pgtype=Homepage

van Dijck, J. (2014). Datafiction, dataism and dataveillance: Big Data between scientific paradigm and secular belief. Surveillance \& Society 12(2): 197-208. 


\title{
4. AUTONOMOUS VEHICLES, MAPS \& TRUST
}

\author{
Julian Thomas \\ RMIT University \\ Rowan Wilken \\ RMIT University
}

Autonomy, in vehicles as elsewhere, involves predictive, decision-making functions, requiring large amounts of data and information. Autonomous vehicles now work constantly to locate themselves and other objects in their immediate environments. These vehicles also need to make decisions in real time, which requires a high level of on-board processing capacity, and a practical division of processing labor between the car and the cloud. Local processing is highly sophisticated, as autonomous vehicles rely on machine learning and deep learning to recognize proximate objects.

These aspects of the vehicle's "machinic complex"-the integral roles of data acquisition and management, and local processing — may be strongly associated with autonomy, and the transformation of cars into decision-making machines. In this paper, we use the example of mapping to argue that these capacities are not unique to the emerging technologies of autonomous vehicles, but that they constitute a vital, yet largely neglected, aspect of the contemporary "automobility system" (Urry, 2007, p. 115). In our account, maps are not only essential to autonomous vehicles for their role in their operation, but also for their governance, political economy, and trustworthiness. Maps are critical devices for accountability and transparency in autonomous systemsbut their significance in this respect is not new.

In this paper, we develop our argument in two steps. In the first part of this paper, we provide some historical context by tracing a series of key points in the development and gradual incorporation of maps into automobiles in order to explain the central place that this particular kind of data has had in the development of human trust and control of vehicles, and now in autonomous vehicles.

\section{A Contemporary History of Cars and Maps}

Cartographic information and communication in the form of road maps, atlases and directories were an essential in-car accessory from the very earliest days of automotive transport (Akerman 2006). These maps-as well as other media, such as photo-auto guides, which combined textual and other instructions with landscape photography and maps in published books (Thielmann, 2016)—were both sources of vital information and eloquent symbols of the power and possibilities associated with mobility. Maps were necessary because automobiles were entirely dependent on the existence of special road infrastructures-a widely-recognized limitation of the new technology of automobiles-but they conveyed great capabilities for long range travel and urban convenience.

The mechanical control of maps was seen as a necessary early step in enhancing the control of motor vehicles. In-car mechanized maps, or mechanical guidance systems, 
appear early in this history. The Jones Live-Map from 1911, for example, consisted of a turntable slowly rotated by a gear train connected to one of the vehicle wheels by a flexible shaft. Related technology appeared, ca.1930, in the form of the Italian-made Iter Avto. This was a dash-mounted device containing a scrolling paper map that was loaded into the system to correlate with a specific route.

A major step towards the development of modern, digital in-car navigation systems came with the creation of the Automatic Route Control System (ARCS) that was designed in 1970-1971 by the US-based Command Systems Corporation. ARCS was the "first autonomous route guidance system to use an on-board digital computer with digitized maps and map-matching software in conjunction with a dead-reckoning subsystem" (French, 2006, p. 272) that used its map-matching software to "correlate the apparent vehicle route with the actual route map stored on a digital tape cartridge" ( $p$. 272).

Commercially released in-car navigation systems began to emerge from the early 1980s, using dead reckoning (Newcomb, 2013). Perhaps the key change occurred in 2000 when more accurate GPS services for non-military use were permitted (Ceruzzi, 2018). This led to the proliferation of navigation-focused GPS-driven technologies, first in the form of portable devices developed by TomTom, Garmin and others, and later as apps for smartphones (Newcomb, 2013). In the face of many well-known failures, cars have progressively and continuously integrated mapping, increasingly sophisticated display technologies, and autonomy over the last four decades, with considerable evidence of user acceptance and dependence.

\section{Maps and Autonomous Vehicles}

Building on the historical analysis, in the second section of this paper we position maps and maps data-alongside other rapid technological innovations related to mobile and autonomous vehicle navigation (including LIDAR), and vehicle-to-vehicle communication systems-as crucial to the successful development of trust in increasingly autonomous vehicles. Our argument in this section of the paper is that maps, and the data streams they generate and combine with, are not a layer on top of autonomous vehicle systems-they are integral to their operation and human use. They are also likely to be crucial to the future trustworthiness-or otherwise-of these systems.

Precision maps are vital at the orientation and decision stages of autonomous vehicle operation. They enable vehicles to make critical predictions. The particular challenge for driverless cars, as autonomous vehicle development pioneer Sebastian Thrun explains, is to "map the environment while simultaneously determining the [car's] position relative to this map" (Thrun \& Leonard, 2008, p. 872). "Key enablers" in responding to this challenge are what Thrun and Leonard refer to as "simultaneous localization and mapping" (SLAM) processes (p. 871), whereby the vehicle operates as a communication platform to combine, in real-time, finely granulated precision maps information to orient the vehicle, with supplementary perception data generated from the vehicle's arrays of sensors, and with both sets of data continually interpreted and acted upon, then reinterpreted and acted upon, etc., by the decision-making processor. 
As vehicles have acquired more autonomous capabilities, they have also become specialized mapping machines, both with and without direct human involvement. For this reason, maps have become increasingly strategically and operationally important for the transport and communications platforms of the near future.

\section{References}

Akerman, J. R. (2006). Twentieth-century American road maps and the making of the national motorized space. In Akerman, J. R. (ed.) Cartographies of Travel and Navigation (pp.151-206, 321-330). Chicago: University of Chicago Press.

Ceruzzi, P. E. (2018). GPS. Cambridge, MA: MIT Press.

French, R. L. (2006). Maps on wheels: The evolution of automobile navigation. In Akerman, J. R. (ed.) Cartographies of Travel and Navigation (pp. 260-290, 343-346). Chicago: University of Chicago Press.

Newcomb, D. (2013). From hand-cranked maps to the cloud: Charting the history of incar navigation. Wired, April 10. https://www.wired.com/2013/04/history-in-carnavigation/

Thielmann, T. (2016). Linked photography: A praxeological analysis of augmented reality navigation in the early twentieth century. In Gómez Cruz E and Lehmuskallio A (eds.) Digital Photography and Everyday Life: Empirical Studies on Material Visual Practices (pp. 160-185). Routledge: London.

Thrun, S. \& Leonard, J. J. (2008) Simultaneous localization and mapping. In Siciliano B and Khatib O (eds.) Springer Handbook of Robotics (pp. 871-889). Berlin: SpringerVerlag.

Urry, J. (2007). Mobilities. Cambridge: Polity 